\title{
Das possibilidades de desaparecer na
}

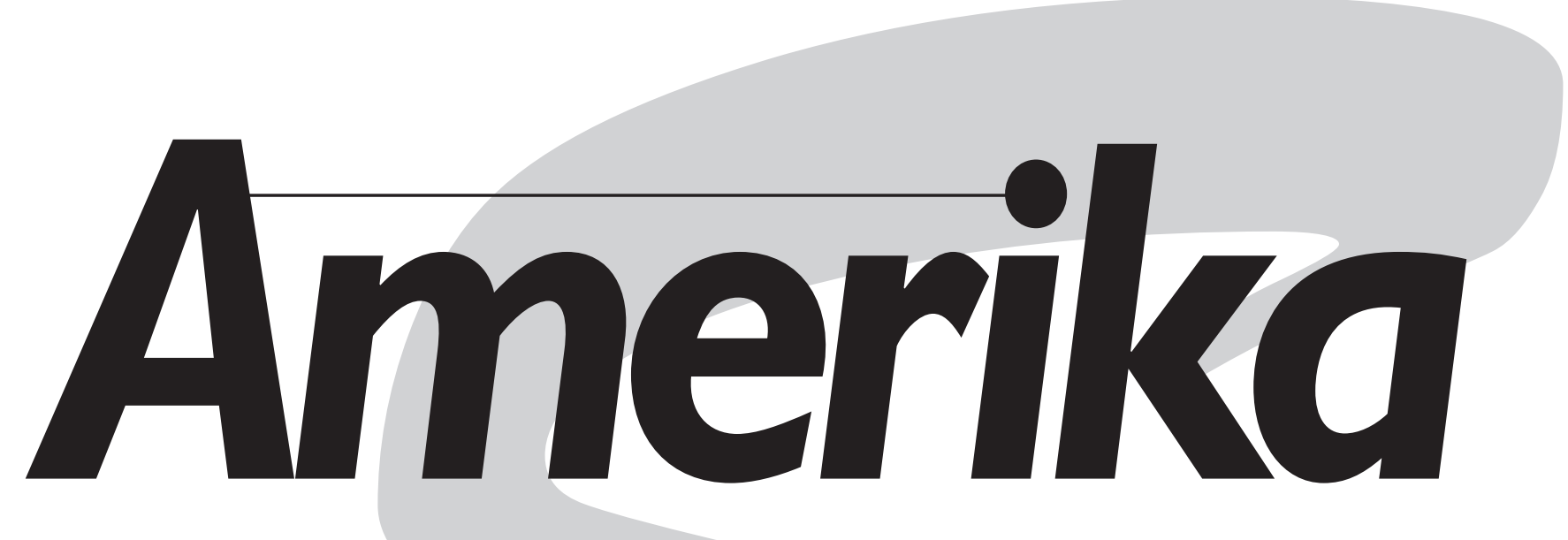

ENRIQUE MANDELBAUM

ENRIQUE

MANDELBAUM

é psicanalista e autor do

livro Franz Kafka: um

Judaísmo na Ponte do

Impossivel(Perspectiva).

0 Desaparecido ou

Amerika, de Franz Kafka

tradução, notas e posfácio

de Susana Kampff Lages,

São Paulo, Editora 34 ,

2003.
Susana Kampff Lages oferece ao público leitor de língua portuguesa uma oportunidade imperdível para todos aqueles que sabem que a experiência de leitura é uma via insubstituível para um modo de dotar de sentido a matéria viva de que somos feitos e de que é feita a insólita experiência de nosso acontecer histórico. O prazer da leitura é sempre o encontro de uma ressonância de significados capazes de nos acolher, despertando e pondo em atividade o lastro de nossas pegadas, as evidências de nossa existência: o tecido de nossas memórias. E, ao acolher-nos assim, a leitura redinamiza todo esse amálgama de pensamentos, ações e sentimentos que nos põem em movimento, promovendo ao 
mesmo tempo intimidade e estranheza, isto é, a possibilidade de renovar-nos. E mesmo para aqueles que ainda precisam de uma experiência inaugural sobre o quão estranhável e familiar ao mesmo tempo pode ser a matéria que absorvemos através da leitura, o texto de Kafka promove uma claridade sob cujo fulgor perturbamo-nos a ponto de deixar engendrar-se um espanto a respeito de nós, de nossas crenças, nossos conceitos e teorias, e sobre as instituições culturais, políticas e de trabalho que nos organizam e nas quais existimos. Com Kafka, o mundo estremece. E o fantástico empenho de Susana Kampff Lages, pondo em atividade seus amplos conhecimentos da língua alemã, de literatura e do próprio autor, transforma sua versão da primeira obra de Kafka de maior fôlego numa importante experiência de leitura que, integrada às realizações de Modesto Carone, entre outros tradutores desse autor checo que escrevia em alemão, permite à língua portuguesa acolher o insólito das profundezas da obra kafkiana.

O trabalho de Susana foi realizado sobre o tex to da edição crítica alemã publicada em 1983, que se caracteriza por estabelecer um diálogo crítico com a versão organizada pelo amigo mais próximo de Kafka, Max Brod, em 1927, à qual este deu o nome de Amerika. A nova versão alemã, em que o editor Jost Schillemeit acrescenta algumas variantes do texto presentes nos manuscritos originais, bem como insere em notas de rodapé trechos riscados pelo próprio autor e destaca as pequenas variantes que Max Brod promoveu sobre o manuscrito original, ganhou o título de Der Verschollene (ODesaparecido), respeitando o nome com que Kafka mais freqüentemente referia-se a esse seu trabalho. Susana absorve toda essa realização do editor alemão, mas o mais interessante em sua versão é deixar ainda de pé a importantíssima realização originária de Brod. Isto é, ela não segue a via a nosso ver equivocada de subestimar ou reduzir a importância do trabalho do fiel amigo de Kafka na preservação e divulgação desse autor que, em vida, apenas tinha o seu trabalho reconhecido por alguns poucos e esclarecidos leitores de um círculo muito reduzido de pessoas. As novas versões críticas - a mais recente, um empreendimento em andamento da Editora Stroemfeld de Frankfurt, A HistorischKritische Ausgabe sämtlicher Handschriften, Drucke und Typoskripte (edição histórico-crítica de todos os textos manuscritos, impressos e datilografados) -, mais do que redinamizar a condição fragmentária e inacabada do texto kafkiano, pretendem pôr em evidência essas qualidades inegavelmente presentes na obra desse autor, de quem somente uma parte menor da produção conseguiu ganhar a condição plena de obra literária acabada - se levarmos em consideração o fator de acabamento editorial final em forma de livro -, mantendo a maior parte de seus escritos a qualidade de anotações pessoais, rascunhos registrados num sem-número de pequenos cadernos, ainda distantes de um ponto final que lhes permitissem ganhar o título de obra literária pronta para publicação, quando de sua morte. O que queremos destacar é que o estado em que se encontrava a sua produção escrita em 1924 - ano de seu falecimento - não prescindia, para ganhar o caminho da publicação, da mão de um editor, de alguém que, por assim dizer, juntasse os cadernos e amarrasse os fragmentos e partes dos textos que, como sabemos, Kafka costumava escrever a partir de uma disciplina pessoal por demais singular, cujo resultado se caracteriza, por um lado, pela extrema clarividência de cada sentença, a impressionante "facilidade" com que as orações vão se sucedendo e se organizando num registro limpo e desimpedido, quase livre de correções posteriores do próprio autor e, por outro, por interrupções abruptas da matéria narrada, saltos de perspectiva na abordagem utilizada, retomadas de personagens em situações novas de aparentemente frágil conexão com o acúmulo narrativo anteriormente realizado e o aproveitamento de fragmentos de um projeto literário maior em novas situações, suscitando assim, mais do que uma autonomia das partes de sua escrita em relação ao todo, a emergência de um todo escritural que é 
feito de fragmentos textuais, desdobramentos tensionados de uma experiência na escritura e com a escritura. Ele próprio, em sua seleção de material para publicação, pensava integrar fragmentos de diversos trabalhos seus, como por exemplo quando das tratativas para publicação, na coleção do editor Kurt Wolff - Der Jünste Tag -, de um volume seu cujo título ele pede ao editor que seja Filhos, e que integraria espaços textuais tão diversos quanto aquele que constitui o primeiro capítulo do romance traduzido por Susana - O Foguista -, A Metamorfose e $O$ Veredicto, todas produções de 1912, ano em que Kafka encontra o vértice principal de sua forma literária.

Numa carta a Kurt Wolff de 4 de abril de 1913, Kafka, referindo-se a O Foguista, ressalta seu aspecto fragmentário: "não sei se poderá ser publicado de forma isolada; se bem que não chegue a expor diretamente o completo malogro das quinhentas páginas seguintes, ainda não constitui uma unidade completa. Trata-se de um fragmento, e o continuará sendo; este futuro confere ao capítulo seu melhor caráter de 'completude" " (*). Ou seja, trata-se de um fragmento não tanto porque tenha em si constituída uma totalidade, mas porque, de acordo com a severa autocrítica a que Kafka costumava submeter os seus escritos, algo do que se sucede nas "quinhentas páginas seguintes", da qualidade da escrita, confere uma quase autonomia a essa primeira parte que, por sua vez, amarra-se de algum modo, de acordo com a compreensão do autor, a outras realizações suas, sob um nó geral que ele denomina de Filhos. Como se essas três incursões na escrita pudessem ser compreendidas como variações possíveis de uma história familiar: a precipitação na morte de Georg Bendemann em $O$ Veredicto, cumprindo a condenação paterna ao afogamento; a metamorfose de Gregor Samsa num inseto gigantesco que causa tanto transtorno à casa paterna que, quando a morte chega, o pai pode dizer: "agora podemos agradecer a Deus", em A Metamorfose; e essa espécie de fuga/exílio/expulsão/viagem - o desaparecimento na América - de Karl Rossmann, em O Foguista, "porque uma empregada o seduzira e tivera um filho seu". Três versões sobre a autoridade do pai, o elemento precipitador implícito no destino dos filhos, o nome/nó em torno do qual Kafka acharia possível ver gravitando esses três relatos seus, propondo a existência de um diálogo subterrâneo e silencioso entre as diversas partes de sua obra - diálogo existente, na verdade, tal como em qualquer outro autor, mas que, no caso de Kafka, amplifica-se, uma vez que a forma fragmentária de seus rabiscos pessoais cristalizou-se no instante do desaparecimento dele, possibilitando à sua escrita uma incursão à maneira como Julio Cortázar, de forma mais intencionada, pretendia na abordagem de seu relato Rayuela: como um jogo de armar ou o salto no jogo da amarelinha, em que o tempo da leitura fica desprendido do determinismo promovido pela característica sucessiva da linguagem escrita e do clássico modo de desenvolver uma história nos romances e novelas. Daí, as intermináveis discussões dos críticos, por exemplo, a respeito dos últimos fragmentos de $O$ Processo: qual seria a ordem premeditada pelo autor desses fragmentos inconclusos e, até mesmo, teria Kafka em mente uma ordem determinada no momento da escrita desses fragmentos? A última pergunta é legítima, uma vez que um dos traços marcantes desse autor é o de suscitar um registro quase que sem memória nem desejo, sem um horizonte passado ou futuro, uma escrita que tem como nascedouro o aqui-eagora do exercício do escritor. Isso pode ser, por exemplo, visto no próprio romance que Susana traduziu, em que grande parte dos giros do acontecer ficcional, bem como dos desdobramentos narrativos, mais do que ter uma ancoragem num acontecer "realista" dos fatos, ou mesmo em modelos ideacionais externos à matéria narrada, emerge como elaborações instantâneas da atividade da escrita de Kafka, como se a matéria escrita fosse uma fabulação reflexiva de sua própria atividade de escritor, elaborada no próprio instante da escrita. E, à medida que o tempo passa, de 1912 a 1924, essa narrativa auto-referenciada, que é quase um registro fabulado das configuF. Kafka, Letters to Friends,
Family and Editors, Schocken Books, 1977 
rações que emergem como ritmos em seu ato de escrever, vai ganhandocada vez mais importância, a ponto de tomar quase por inteiro o espaço textual de um de seus últimos relatos escritos, A Construção, em que toda essa terrível fabulação a respeito dos procedimentos assustados de um animal que vive abaixo da superfície da terra pode ser compreendida como as desesperadas estratégias de construção de um sentido que se desdobre através das sentenças escritas, suscitando assim uma correspondência biunívoca entre o exercício da escrita e a fabulação realizada, correspondência esta que lhe permite, por assim dizer, originar ao mesmo tempo e na mesma matéria narrada tanto uma poética, uma legitimação da forma narrada, quanto uma narrativa, ou seja, um texto que tem sua forma justificada na própria forma que realiza. Desse modo, emerge uma realização dotada de autonomia expressiva, tão magistralmente elaborada e com tanto rigor calibrada na forma que muitas de suas narrativas podem ser compreendidas como poesia em prosa, se reservarmos à poesia o lugar do rigor, onde cada palavra significa, onde nenhuma letra está de graça. Ou melhor, onde todas as letras estão convocadas sob o rigor de uma graça. Mas Kafka não é Julio Cortázar, e a condição fragmentária de seus relatos o inquietava profundamente. Não via neles propriamente uma realização positiva como escritor, mas fracassos eficazes para registrar o estado de coisas de sua situação no mundo. A "falta de chão, ar e mandamento" da qual ele se queixava ininterruptamente suscita essa escritura que é uma espécie de corrida atrás de si própria e que termina por constituir-se num dos mais contundentes registros a respeito da condição de solidão do homem moderno. E, como Kafka era um autor para quem a arte, ou seja, a atividade literária, tinha um forte compromisso com a verdade, a sua escrita nada mais devia do que realizar sua verdade existencial, sua verdade de "falta de chão, ar e mandamento", sua condição de fragmento - solteiro, desprendido de um passado mais significativo, sem um horizonte futuro, completamente mergulhado num aqui-e-agora instável.
No posfácio que acompanha a versão de Susana, seu ensaio "Das (Im)possibilidades de Traduzir Kafka”, ela ressalta, entre tantas chaves de leitura da obra kafkiana que ela arrola com generosidade e extremo conhecimento da fortuna crítica desse autor, a íntima relação existente entre os escritos de Kafka e "sua condição de judeu na Praga das primeiras décadas do séc. XX". $\mathrm{E}$, de fato, o que impressiona em Kafka é como essa escrita, por um lado tão fantástica, isto é, tão desprendida de um substrato realista, seja ao mesmo tempo tão extraordinariamente expressiva da condição dos homens nos dias de hoje, a ponto de o poeta Auden dizer que aquilo que Dante Alighieri foi para a sua época, Kafka oé para a nossa. E se o texto de Kafka se mostra tão eficaz - apesar de todo o fantástico que o habita na sua função de mímesis, é exatamente graças a esse bem-sucedido isomorfismo que Kafka consegue gerar entre a forma e o conteúdo narrado. Por isso, a experiência de ler Kafka, além de ser inesgotável, é insubstituível. Isto é, apesar de Kafka nos deixar como herança a contragosto seu ele verdadeiramente teria gostado que todos os seus rascunhos, ou a maior parte deles, tivessem desaparecido com ele - o que seja talvez o retrato mais verdadeiro de nossa condição de existentes, da nossa vida em sociedade e da nossa vida em família nos tempos modernos, toda a reflexão que sobre os seus escritos possa ser feita, toda elaboração que dela possamos abstrair,fica sempre aquém da própria matéria narrada que esse autor realiza. Kafka não teoriza sobre os homens, nem sobre a literatura. Não é um crítico, não é um pensador, nem tampouco um historiador. Ele é um escritor de ficções, um fabulador, e seu empenho reergue a literatura à condição de poder ser, como em alguns outros escritores nucleares - Shakespeare, por exemplo, o próprio Dante, Dostoievski, Cervantes, Machado de Assis, Guimarães Rosa (a lista pode ser extensa e não fechada, mas bem seleta)-, um espaço privilegiado para a manifestação do humano, em todo seu modo multidimensional de ser. Kafka pensa, Kafka historia, Kafka critica, Kafka anali- 
sa, Kafka teoriza, fabulando. E, por isso, tomar a sério a sua narrativa, adentrar o campo ficcional e acompanhar as estranhas, angustiantes e até risíveis situações de suas personagens seja o melhor modo de abordar Kafka. Porque, com certeza, há um mundo em Kafka, mas é um mundo que tem sua fonte na própria matéria ficcional que ele constrói. É sua quase milagrosa capacidade de fabulação transparente que transforma seus textos em suportes para um inesgotável exercício de exegeses a partir dos mais diversos vértices, podendo mobilizar todos os campos da crítica literária. E o modo como Susana nomeou sua versão desse romance de Kafka-O Desaparecido ou Amerika - é um feliz achado, por um lado, como dizíamos, por honrar o trabalho de Max Brod e, por outro, por acolher as possibilidades de novas leituras dessa impressionante obra. O Desaparecido ou Amerika nos obriga a levar seriamente em consideração os dois suportes essenciais de toda essa narrativa: por um lado, a situação pessoal do jovem Karl Rossmann e, por outro, a descrição desse ambiente urbano altamente tecnologizado, industrializado, burocratizado, onde sempre multidões se apinham em seu ir e vir, num trânsito ininterrupto de carros e corpos, mas com possibilidades reduzidíssimas de redundarem em encontros que se sustentem e permitam a cada um dos implicados experimentar uma relação ao mesmo tempo acolhedora, reasseguradora, integradora, fortalecedora, sem que isso venha a significar um acréscimo de onipotência, de algum modo um sentimento de poder, de superioridade, que sobrepõe o pessoal a tudo e todos, fertilizando assim um terreno propício para o enraizamento do mal, de um mal moral, em que todos tendem a julgar equivocadamente a todos e onde cada um pode ser, de forma quase inocente, responsável pelo sofrimento de quem está ao seu lado. Ali, todos vestem algum tipo de traje e todos realizam ou sofrem alguma forma de ultraje. Karl Rossmann é reiteradamente repreendido por personagens plenamente integradas ou, ao menos, plenamente uniformizadas, isto é, completamente encapsuladas nas funções que desempenham em organizações tão complexas quanto o navio que o despeja nos portos do novo continente, ou o Hotel Ocidental, em que, por algum tempo, é acolhido/empregado como ascensorista. E é também repreendido por personagens marginais às estruturas instituídas, tais como o andarilho francês Delamarche.

Em nenhuma outra obra desse autor, a paisagem externa ganha tanta relevância na descrição como nesse texto. Kafka é um autor que, sem sair de Praga, viajava extensamente através da leitura e em sua escritura. Ele, cuja obra é tão implicada com a Praga do início do século XX, sua cidade natal, em seus escritos explora regiões para além dos mares, no Ocidente, e também no leste. E ele incursiona também por toda a literatura universal, fazendo dela o suporte para exercícios de escrita que ressignificam passagens bíblicas, mitologias gregas, autores barrocos, do classicismo, do romantismo, do simbolismo, do naturalismo e do realismo, além da literatura psicológica russa. Enfim, em sua escrita parecem convergir as mais amplas experiências da escritura dos homens. Diversas narrativas suas fazem do Oriente o suporte para suas fabulações, tais como o relato A Muralha da China e tantos outros nos quais um substrato oriental erguido à condição de território lendário serve para sustentar uma fabulação que gravita entre o parabólico e o alegórico. Nesses relatos situados ao leste de Praga, o contexto é amplamente abstraído, sendo suas implicações orientais territorializadas numa escrita que opera muito mais em ressonância com a literatura chinesa clássica do que em suportes geográficos ou descrições de paisagens urbanas mais elaboradamente realizadas. O mesmo não se dá aqui, em sua visita, através da escrita, ao Novo Mundo. Aqui, como salientávamos anteriormente, a paisagem ganha precedência no trabalho descritivo que Kafka realiza. Toda essa construção humana, erguida quase que à condição simbólica através de nomes como o da cidade de Ramsés - que faz ressoar, em cima dessa história de imigrantes, ecos da construção de cidades por escravos, tal como nar- 
rado no texto bíblico - ou do próprio Hotel Ocidental - essa gigantesca instituição que hospeda e emprega multidões a partir de um regime de funcionamento extremamente burocratizado, no qual a garantia de sossego e comodidade de alguns serve como parâmetro para as normas de funcionamento e legitima o frenesi exaustivo de todos, o autoritarismo dos chefes e a insegurança, fragilidade, esgotamento e desvitalização de outros -, ganha um espaço importante, como que querendo fixar para o sofrimento uma matriz sócio-histórica demasiadamente humana.

O leitor poderá surpreender-se, ao aventurar-se por Amerika, com a incrível atualidade - em Kafka, quem envelhece não é a obra, mas os homens e as suas instituições - das cruas descrições das diversas dimensões do acontecer da vida humana nesse entorno onde tudo parece gravitar em torno do lema "business is business": a opressão e a violência do mundo do trabalho, suas precárias condições, a incerteza diante do desemprego, a extrema burocratização e especialização, a paralisante alienação, a máquina de entretenimento que parece convocar e acolher a todos num espetáculo em que cada um pode desempenhar algum tipo de função, ora de anjo, ora de diabo, e onde a própria democracia, isto é, os princípios de soberania e de regime de governo caracterizados pela liberdade de escolha dos governantes e pelo controle da autoridade, reduz-se a espetáculos noturnos e soturnos de luzes e sons desafinados, quase ruídos, com pouca ou nenhuma esperança de servirem para a expressão das reais necessidades e anseios da multidão de homens. Em Kafka, o mal se banaliza, antecipando em ficção a teorização de Hannah Arendt sobre a suspensão do senso moral em organizações totalitárias, o conluio de todos com o espetáculo do sofrimento e a colaboração na injustiça. Énesse aspecto que a paisagem Amerika ganha relevância nesse romance. A nosso ver, tem razão Susana quando traz à cena a reflexão de Walter Benjamin sobre o processo de desdobramento, mais do que de desenvolvimento, presente na obra de Kafka em geral, mas que ela situa na relação entre os diversos fragmentos/capítulos desse romance. Nesse sentido, o Theatro de Oklahama, mais do que uma nova etapa, dessa vez promissora, de acordo com alguns críticos, em relação às etapas anteriores - territórios da Amerika vividos por Karl Rossmann (a casa do tio, a casa de campo do Sr. Pollunder, o Hotel Ocidental, a habitação junto a Robinson Delamarche e Brunelda) -, é um desdobramento das cenas já narradas, à maneira de variações de um mesmo contexto em que se insinua ora a esperança, capaz de promover um investimento dos envolvidos para com esse contexto, ora o conluio funcional e emocional para dotar os corpos, gestos e falas de competências para se reduzirem a ser algo assim como engrenagens do poderoso mecanismo social, que engloba a todos e acolhe todos os homens que ali chegam, mais do que na condição de imigrantes, como sobreviventes despejados nessa nova paisagem histórica regida por um compasso tecnológico.

Assim, nessa vida muito amarga e na qual o pior pode acontecer quando tudo parece estar no caminho certo, há lugar para todos, sejam estes originários da Pomerânia, da Irlanda, da França, do Império AustroHúngaro ou da Alemanha. A Amerika é uma globalização, um ponto no acontecer dos homens para o qual parece convergir toda a humanidade. Nesse sentido, a Amerika é tão abstrata quanto a China de A Muralha da China. Não se trata propriamente de uma descrição naturalista do que se passa nos Estados Unidos da América, mas sim de uma construção realizada nesse território, de uma leitura crítica feita a partir da crença alardeada de que esse país teria se erguido como um lar para a proteção e asilo de todos os perseguidos e martirizados, de todos os expulsos e acuados de todas as partes do mundo - crença tão em voga na Europa da virada do século, principalmente entre as populações judaicas que, nesse período, sofriam um intenso deslocamento migratório em direção ao Novo Mundo, para "fazer a América". No romance, esse ambiente é, ao mesmo tempo, hostil e re- 
ceptivo, acolhe mas não propriamente integra. E é em torno dessa estranheza, que problematiza a crença na possibilidade de continência do humano num novo futuro, que Kafka parece fazer questão de projetar um mundo do amanhã, um futuro tecnocratizado, acentuando traços de progressos técnicos tão inusitados quanto o de uma escrivaninha que tem a competência de se refazer, numa mecânica insólita, ou aparelhos de telefonia em complicado diálogo operacional com homens completamente assoberbados e eletrizados em regê-los, ao mesmo tempo em que precisam lidar com as demandas do entra-e-sai de um público abarrotado de perguntas e demandas. Nesse sentido, o relato tem um quê de ficção científica, como se fosse uma novela de antecipação, como se Amerika fosse a projeção de um amanhã, já presente no início do século XX.

Mas esse romance não é apenas sobre a Amerika. É também sobre o desaparecido Karl Rossmann, um jovem de 16 anos em inquietante estado de exegese acerca de seu entorno. Perturbado por fora, mas também perturbado por dentro, porque em Kafka o modo como o mundo se organiza diz algo muito importante a respeito da condição humana, mas não de toda a sua complexidade. Em Kafka, a organização sociopolítico-cultural dos homens é responsável em grande parte pelo peculiar traçado da condição humana, mas esta não se reduz a um produto do entorno. Nem o sofrimento provém exclusivamente do estranhamento e da hostilidade do mundo exterior. Ethos e cosmos se integram, mas um não se dilui no outro.Em Kafka, um agulhão de estranhamento parece estar implantado nas próprias entranhas de cada homem e impede a possibilidade de uma síntese pessoal estabilizadora. Karl Rossmann, o jovem, tem a competência de seduzir e ser seduzido, de observar as coisas ao seu redor, levá-las em consideração, articular gestos e atos adequados, ganhar a confiança de alguns e até certas benesses, mas, apesar disso, perde-se interna e externamente, como se fosse sujeito a forças maiores do que ele - advindas tanto do campo cultural quanto do orgânico - que martelam insistentemente e com imperiosidade em seu corpo e através do corpo.

De todas as personagens principais criadas por esse autor - estamos pensando em Gregor Samsa, Georg Bendemann, Joseph $\mathrm{K}$ e $\mathrm{K}$-, esta é a mais bem equipada para lidar com toda essa estranheza ou, ao menos, a que se mostra com mais potencialidade para levá-la em consideração, com perplexidade e até dotado de um certo espaço para manobras. Ele se apropria do que vive e, de certo modo, reinventa-se em cada situação, diferentemente de Samsa, por exemplo, a quem, uma vez assumida a forma de sua metamorfose, nada mais resta do que se familiarizar com ela e aperfeiçoar o interjogo das partes que o constituem, para o melhor desempenho das suas reduzidas mas não por isso menos complexas atividades da nova rotina a que se vê submetido. No caso de Karl Rossmann, há um percurso pessoal transformador, desde o seu primeiro encontro inesperado com o foguista, logo no primeiro capítulo da novela, quando, desamparado, perambula perdido pelo navio atrás de seu guarda-chuva esquecido e dá de cara com esse enorme homem responsável pelo trabalho das máquinas que põem em movimento o navio - um homem cheio de experiências e navegações, mas que está prestes a perder o seu posto, encontrando-se, portanto, numa situação de tanto desamparo quanto a do jovem Karl Dizíamos que há um percurso transformador porque o Rossmann que é aceito no Theatro de Oklahama, na parte final do livro, ou o Rossmann que toma conta de Brunelda são e não são o mesmo. Existe quase um consenso entre os críticos da obra de Kafka de que esse relato guarda características daqueles romances de formação, como os de Charles Dickens, por exemplo, em que as personagens aprendem com a experiência e se desenvolvem a partir dela. E são esses mesmos críticos que apontam um elemento problematizador presente nesse texto que põe em questão todo esse gênero, ao sustentarem eles que, mais do que aprender com a experiência, Karl Rossmann, por assim dizer, vai desapare- 
cendo à medida que suas experiências de mundo vão se sucedendo. Dar-se-ia algo assim como uma queda pessoal, mais do que uma elevação. Essa é uma leitura possível. Mas, em todo caso, está presente uma transformação da personagem bem mais ampla do que vemos nas outras personagens a que nos referíamos. Todos julgam Karl Rossmann, alguns favoravelmente, outros desfavoravelmente. Estes últimos tendem a precipitá-lo para a infelicidade, enquanto os primeiros resgatam-no numa acolhida que promove reconhecimento e reparação de si. Eé do embate dessas duas formas de experiência que depende o porvir de Karl Rossmann. Mas ele, comodizíamos antes, parece ser dotado de um certo campo de manobras, isto é, de uma propensão a realizar um futuro, talvez impossível, no qual conseguisse transcender esse embate tanto com o mundo externo quanto consigo próprio. O sobrenome Rossmann encerra, em alemão, uma duplicidade cavalo-homem -, e talvez o aprendizado principal que Rossmann deve realizar, se é que não o realiza, é o de ser cavaleiro de si. $E$, se bem que ele fracasse nas aulas de hipismo que o tio Jakob lhe oferece Rossmann parece não ser feito dos atributos que sustentam e erguem os cavaleiros da Amerika-, no hipódromo onde se fazem as inscrições de todos que queiram fazer parte do grande Theatro de Oklahama, o cavaleiro Rossmann parece atuar sem perder a esperança, mesmo quando se apresenta, diante dos oficiais responsáveis pelo recrutamento desse grande teatro, sob o nome de Negro, ou seja, como esses homens que, num determinado momento do processo de desenvolvimento da América, foram reduzidos quase que à condição animal. A equação cavalo/homem, animal/ homem parece ser o nó para o qual confluem as impossibilidades tanto externas quanto internas que fragilizam Rossmann. O externo pode fazer da dimensão humana do cavalo/homem uma redução à condição de cavalo, mas o interno também pode promover a mesma redução. E parece ser um valor dessa Amerika o ginete que é amo e senhor de seu cavalo. Rossmann fracassa nesse intento mas, se não cede totalmente, se tem essa margem para manobras, talvez seja porque atue nele esse desejo que Kafka descreve em sua Contemplação, livro publicado em 1913 no qual, entre as iluminações que o compõem, está “O Desejo de Ser Índio”. Aliás, nesse pequeno livro composto de 18 contemplações, três delas fazem do cavalo, de montarias e das corridas de cavalo um suporte para pensar a vida dos homens. São elas "Para que Meditem os Cavaleiros", "A Janela da Rua" e “O Desejo de Ser Índio". Citemos este último:

"Se se pudesse ser um índio, sempre alerta, cavalgando sobre um cavalo veloz, retorcido no ar, sempre às sacudidas sobre a terra estremecida, até largar as esporas, porque não fazem mais falta as esporas, até jogar fora as rédeas, porque não fazem mais falta as rédeas, e apenas se pudesse ver que o campo é uma pradaria rasa, teria então desaparecido a crina e a cabeça do cavalo".

Nesse ágil desejo descrito, cavalo e homem se fundem pela velocidade do galope, e não fazem mais falta nem esporas nem rédeas. E até o próprio cavalo se esvai na velocidade da marcha. Nesse desejo, manifesta-se uma resolução diferente da dicotomia cavalo/homem. Se, a partir de Freud, compreendemos que o preço a ser pago pelo processo civilizatório é o acréscimo de rédeas e esporas, aqui Kafka descreve uma síntese diferente, na qual a velocidade do galope funde cavalo e cavaleiro a ponto de fazê-los desaparecer. Se Rossmann está a caminho ou não de alcançar essa síntese de si, se Rossmann está a caminho de tornar-se um índio ou, ao contrário, se está cada vez mais sucumbindo diante da pressão de forças do par cavalo/homem, é uma questão que cada leitor terá oportunidade de tomar para si, entre tantas outras, ao adentrar em Amerika graças ao empenho de Susana Kampff Lages e assistir a um retrato da Amerika em que todos cavalgamos aos tropeços e atropelando os outros. 